\title{
ANIMAL LAW: ETHICS, SOCIETY AND CONSTITUTIONS
}

\author{
TOMASZ PIETRZYKOWSKI ${ }^{1}$ \\ ${ }^{1}$ University of Silesia in Katowice, Faculty of Law and Administration, Research Center for Public Policy \\ and Regulatory Governance, Bankowa 11b, 40-007 Katowice, Poland. ORCID: 0000-0003-0428-7021, \\ Email: tomasz.pietrzykowski@us.edu.pl
}

\begin{abstract}
The paper discusses and criticizes views on various aspects of the situations of animals within human societies offered by authors presenting at the seminar held at the Research Centre for Public Policy and Regulatory Governance. They include legal, ethical as well as socio-psychological problems about animal welfare and the attempts to improve the conditions in which animals are treated. The author hints at the theoretical background as well as implications of some of the ideas that are advocated in the ongoing legal and ethical debates over animal welfare. The discussion aims to shed some light on how the cross-disciplinary studies and exchanges that include biologists, psychologists, sociologists as well as legal researchers may contribute to numerous controversies in the contemporary animal law scholarship. KEYWORDS: law, animals, constitutions, ethics, welfare, status, rights
\end{abstract}

The domain of animal studies remains a thoroughly interdisciplinary project, linking natural scientists with philosophers, sociologists, lawyers and specialists in many other fields. It is crucial, therefore, that the discussion of animal issues take place across traditional boundaries of research disciplines. The seminar on animal law in the context of ethical, social and constitutional consideration of the protection of animals, held on May 22019 at the University of Silesia in Katowice, is an excellent example of such a cross-disciplinary event. It was convened by the Research Center for Public Policy and Regulatory Governance, which was established at the University of Silesia in 2018 to deal with all kinds of public and legal policy involving the need to solve regulatory problems. One of the main focuses of the research pursued at the Center is the legal policy on animal protection with particular attention to reforms of the legal status of animals. The seminar was part of that strand of the Center's activities, and its central objective was to prompt interdisciplinary discussion on various 
issues surrounding the process of constitutionalization of animal protection around the world. The seminar attracted a number of renowned biologists, psychologists, sociologists and lawyers interested in the question of animal protection.

Plenary speeches were delivered by Diana Fleischman and Andrzej Elzanowski. Diana Fleischman is a rising star of evolutionary psychology and one of the most widely known advocates of a sentientist approach to animal ethics. Andrzej Elzanowski is a renowned biologist currently affiliated with the "Artes Liberales" Faculty of the University of Warsaw. Recently Elzanowski has also been elected the chairman of the Polish Ethical Society and remains one of the scientific pillars of the Polish animal welfare movement.

Diana Fleischman's speech was devoted to an evolutionary perspective on understanding animal ethics. She argued that modern animal ethics is based on our ability to recognize animal sentience, which has developed as a by-product of the human practice of hunting and killing animals. Thus, paradoxically enough, our selfish attitude towards animals provided the background without which the compassion for and ethical care of animals could not have emerged.

Nonetheless, according to Fleischman, the evolutionary basis of morality creates also some barriers towards the development of a full-fledged animal ethics that would be able to govern people's attitudes toward animals on a wide scale (on that subject see also Fleischman 2019). These include lack of reciprocity in human-animal contacts and lack of reputational consequences for wrongs done to animals in private (due to their inability to communicate these wrongs to other people). She also discussed the so-called vote-buy gap. What she meant by that was the empirical finding that many more people tend to support bans on animal exploitation than are prepared to refrain from taking advantage of such exploitation individually. This gap seems to have important implications for the further development of animal protection. It may suggest that the approach based on individual persuasion to alter habits entailing industrial animal exploitation (such as adopting veganism or giving up other kinds of animal products) may be even more ineffective in comparison with lobbying to improve legal standards of animal treatment than is ordinarily assumed.

This thought was also buttressed by the argument and data offered in a speech delivered at the seminar by Wlodzimierz Gogloza. He compared the modern campaigns aiming at changing attitudes toward consuming animal products to the abstention movement in the $19^{\text {th }}$ century. Efforts to appeal to peoples' conscience in order to persuade individual citizens to voluntarily give up using the products of slave labour largely failed. Slavery could be effectively combated only by political decisions and legal bans. Hopes that the effects could also be achieved by means of individual conversions prompted by moral argument were futile.

According to Gogłoza, this is an important historical lesson for advocates of the cause of animal rights today. It is confluent with the psychological data provided by Fleischman. Both the historical and psychological views strongly support the legal approach to animal protection that focuses on lobbying lawmakers for changes to the law so that cruel forms of animal exploitation shall either be banned or will become economically unprofitable due to improved welfare conditions that corporations have 
to meet.

Andrzej Elzanowski spoke on another kind of gap, namely the one between raising awareness of animal suffering and the "business as usual" reality of the animal products industry. He inquired why the ubiquitous public declarations of compassion and care for animals become ever more distant from the brute reality of animal exploitation, which continues to flourish without any real progress being made to alleviate it. Seeking an explanation for this gap, Elzanowski argued that it needs elucidation of a difference between personal morality and ethics. The development of sound, scientifically informed and rational ethical theories are not accompanied by corresponding changes in popular morality. As the latter remains unaffected, the discrepancy between the level of ethical progress and the positive morality governing individual behaviour increases.

By personal or positive morality, Elzanowski meant the actual psychological attitudes based on emotions and normative reactions that emerge from individual experience and internalized ways of conceiving the world shaped by one's own socialization process. Morality so conceived is hardly controlled by ethics, that is, reflective thinking and argumentation which takes place among a relatively small number of people who are capable of post-conventional examination of the dominant patterns of behaviour constituting the positive morality of their time.

That is why scientifically-informed awareness of the complexity of animal consciousness is rarely perceived as having any normative implications. Animals cannot reciprocate; that is, they lack the vital capacity that was the evolutionary cornerstone to the development of morality among humans. Thus, conventional morality does not regard animals as authorized parties to moral relations. As animals in their standard relations with people can seek neither revenge nor reward for what is done to them, there is no ground on which conventional morality could stand. This argument, one may add, is a modern variation and empirical substantiation of the classical explanation of animal subordination offered by David Hume ${ }^{1}$.

Similar to Fleischman, it is animals' general inability to reciprocate that Elzanowski identified as one of the main obstacles to extending conventional morality to non-human species. The other major obstacle he located in the phenomenon described by the so-called terror management theory (Pyszczynski, Solomon, Greenberg 2015). This may suggest that people perceive animals as inferior, purely biological, creatures because they need to hold this view in order to cope with their own awareness of mortality. Therefore, juxtaposing animals to people serves the latter to help them believe in their own allegedly higher and more meaningful kind of existence. This, in turn, underpins conventional morality, making it resistant to the discoveries and scientifically-informed arguments proposed in ethical discourse.

\footnotetext{
${ }^{1}$ Hume famously argued that: "Were there a species of creatures, intermingled with men, which, though rational, were possessed of such inferior strength, both of body and mind, that they were incapable of all resistance, and could never, upon the highest provocation, make us feel the effects of their resentment; the necessary consequence, I think, is, that we should be bound, by the laws of humanity, to give gentle usage to these creatures, but should not, properly speaking, lie under any restraint of justice with regard to them, nor could they possess any right or property, exclusive of such arbitrary lords" (Hume 1998:190).
} 
Thus, to Elzanowski, it is morality, with all its intricacies and psychological and evolutionary entanglements, that should be the main target of the legislation. It is not enough to base legal claims on sound ethical theories, since the latter may diverge radically from the die-hard views of the conventional morality of a given time. The law is, however, able to instigate changes in morality as well, but in much more complex and subtle ways than just imposing duties that are substantially different from those that people find justified in their own moral beliefs.

Speeches were also delivered by three eminent American scholars: Steven Wise, David Favre and Pamela Frasch.

Steven Wise outlined his litigation strategy, which has been adopted by the Non-Human Rights Project, the organization he leads. It aims at seeking a single right to be judicially declared to pertain to even a single animal. That, according to Wise, would make for a breakthrough in judicial thinking about the status, ultimately, of all animals and bring about a change in the most crucial social justice question in history. His American colleague from Michigan State University College of Law, David Favre, argued for seeking recognition of some fundamental rights for dogs rather than for other mammals. Favre pointed out that the widespread human sentiment of treating pets as family members is a much better foundation for a potentially successful legal argument than scientific expert evidence and logically compelling reasoning. Treating some animals as a particular category of "living property" (the term has been coined as a part of the theory of a legal status of animals developed by Favre, 2010) is just a small step from actual recognition of rights and interests of individual animals as a subject rather than objects of the law. Favre believes that dogs may be the best "gateway animals" to try to make that further step to recognizing animals as holders of their own individual legal rights.

The next speaker, Pamela Frasch, Associate Dean of the Animal Law Program at the Lewis \& Clark University School of Law, discussed the question of animal cruelty images in the context of the constitutional protection of free speech. She argued that the case for exempting animal cruelty from the scope of constitutionally protected free speech under American law is actually convincing. The issue is, however, far from being finally resolved and the free speech argument still remains valid under the constitutional regime of the First Amendment. To overcome this, depictions of animal cruelty would have to be conclusively deemed a new category of legally unprotected expressions (Perdue, Lockwood 2014). Although Frasch has not approached the problem from the perspective of the constitutionalization of animal protection, it seems that the difficulty she has addressed is at least partially an example of the imbalance arising from the contrast between constitutional rights of people (in this case - freedom of speech) and the lack of constitutional rank for the legal principles governing the protection of animal interests.

The seminar also included a fascinating sociological session. The paper presented by Geeta Shyam of Monash University, Adelaide focused on an empirical study of the actual attitudes of members of local Australian communities towards the question of animals as property. The study suggests that the majority of people intuitively conceive animals as subjects rather than as property (Shyam 2018). Shyam proposes that 
the results of the research she has carried out can be instrumental in evaluating competing theoretical accounts of animal status in law as well as the viability of many arguments concerning legal reform - namely those that are based on what the community attitudes actually are. Insofar as it is claimed that the law ought to reflect the real attitudes of people, an empirical clarification of those attitudes is needed for the evidence on which legal policy towards animals should be based.

The second speech in the sociological section of the seminar was delivered by Hanna Mamzer from Adam Mickiewicz University in Poznan. She discussed an experiment performed in Poland concerning the perception of pets by children. One of the outcomes of this study showed that children not only tend to conceive animals as their kindred but often place them among the most important members of their families. Interestingly, there seems to be some correlation between the material conditions in which a child lives and the perception of pets. The better off the family, the more critical an animal becomes for the child, and the more often the parents were missing from the family depictions produced by the children. This may suggest, according to Mamzer, that pets may to some extent, serve as substitutes for human relations when parents concentrate on their professional careers.

The paper presented by Birgitta Wahlberg from Åbo Akademi in Turku dealt with the draft amendment to the Finnish Constitution that has been prepared by a team of leading animal lawyers in Finland. The draft of a new article of the Constitution is based on the idea of the recognition of individual animals as holders of their individual interests and the establishment of a constitutional duty to take those interests into account in all decisions that may seriously affect them (Pietrzykowski 2017). Apart from thoroughly thought-over general principles, the bill contains a set of detailed and carefully drafted rules concerning various issues of the situation of animals. ${ }^{2} \mathrm{Un}-$ doubtedly, at the moment the Finnish draft amendment must be considered the best model of constitutionalizing animal protection that has been proposed anywhere in the world. The only part of the draft that may seem questionable is the principle of precaution, according to which all animals should be regarded as sentient as long as there is sufficient scientific evidence to the contrary.

The contribution of Sacha Lucassen concerned analysis of QBA (Quality Behavior Assessment) as the preferred method of examining the welfare of individual animals. She thoroughly explicated the theoretical basis of the QBA methods - namely the assumption that in the case of sentient creatures, their patterns of behaviour ought to be interpreted as expressions of feelings and other subjective states of mind. In this way, external behaviour analyzed by a set of scientifically-informed descriptors can constitute a reliable window onto animals' subjective experience.

The speeches delivered by Tarja Koskela and Amy Wilson pertained to more practical aspects of the legal protection of animals in Finland and South Africa, respectively. Additionally, a guest presentation on animal law in the context of animal activism was delivered by Jakub Stencel, representing Otwarte Klatki (Open Cages) - the leading Polish animal activist NGO.

\footnotetext{
${ }^{2}$ The draft is available at https://www.elaintenvuoro.fi
} 
Each presentation was followed by an intense discussion in which various legal, ethical and sociological themes interweaved. This indicates that at the present stage of development of the animal rights cause in public discourse, these three levels are in no small extent inseparable. In particular, any discussion on constitutionalizing animal protection or taking any other significant step forward in the laws concerning the protection of animals inevitably raises legal as well as ethical and sociological questions and concerns. That is why the most fruitful and productive approach to discussing animal law is to embed it in the interdisciplinary context of philosophical and sociological investigation into the domains underpinning the existing or postulated content of legal or constitutional rules. This was the reason for holding a seminar, the program of which would encompass the constitutional, sociological and ethical aspects of animal law. The proceedings and outcomes of all its sessions demonstrate that the initial idea was unquestionably well-founded.

FUNDING: This report is part of a project performed on the basis of the research grant of the Polish National Science Center (UMO-2017/27/B/HS5/00085). The University of Silesia has been able to establish its Research Center for Public Policy and Regulatory Governance thanks to the funds received from the Polish Ministry of Science and Higher Education within the Program “Dialog” (0179/2017).

CONFLICT OF INTEREST: The author declares no conflict of interest.

\section{REFERENCES}

Favre, David. 2010. "Living Property: A New Status for Animals Within the Legal System.” Marquette Law Review 93: 1021-1071. Retrieved July 14, 2019 (https:// scholarship.law.marquette.edu/mulr/vol93/iss3/3).

Fleischman, Diana. 2019. "Universal Morality is Obscured by Evolutionary Morality." The Evolution Institute. Retrieved July 14, 2019 (https://evolution-institute.org/ universal-morality-is-obscured-by-evolved-morality/).

Hume, David. 1998. Enquiries into the Principles of Morals. Oxford: Oxford University Press.

Perdue, Abigail, Lockwood, Randall. 2014. Animal Cruelty and Freedom of Speech: When Worlds Collide. West Lafayette, Indiana: Purdue University Press.

Pietrzykowski, Tomasz. 2017. Personhood Beyond Humanism. Animals, Chimeras, Autonomous Agents and the Law. Cham, Switzerland: Springer.

Pyszczynski, Tom, Solomon, Sheldon, Greenberg, Jeff L. 2015. “Thirty Years of Terror Management Theory.” Advances in Experimental Social Psychology 52: 1-70.

Shyam, Geeta. 2018. "Is the Classification of Animals as Property Consistent with Modern Community Attitudes?” UNSW Law Journal 41(4): 1418-1444. 


\section{BIOGRAPHICAL NOTE}

Tomasz Pietrzykowski is professor of law specializing in legal theory and philosophy of law at the University of Silesia in Katowice, Poland.

OPEN ACCESS: This article is distributed under the terms of the Creative Commons Attribution Non-commercial License (CC BY-NC 4.0) which permits any non-commercial use, and reproduction in any medium, provided the original author(s) and source are credited.

ARTICLE HISTORY: Received 2019-09-04 / Accepted 2019-11-26 
